\title{
TETRACYCLINE RESISTANCE IN ESCHERICHIA COLI ISOLATES FROM POULTRY
}

\author{
Dragana Ljubojević ${ }^{1}$, Maja Velhner ${ }^{1}$, Dalibor Todorović ${ }^{1}$, \\ Marko Pajić ${ }^{1}$, Dubravka Milanov ${ }^{1}$ \\ ${ }^{1}$ Scientific Veterinary Institute "Novi Sad", Novi Sad, Serbia
}

\section{Abstract}

The objectives of the present paper are the analysis and comparison of the results from available literature regarding the prevalence of tetracycline resistance in Escherichia coli strains isolated from poultry in different countries. Tetracycline is still one of the most commonly used antibiotic in many developing countries both in human and in veterinary medicine. The main reasons are its relatively low cost and availability. Besides that, this class of antibiotics is still used in developed countries for prophylactic and therapeutic purposes. The widespread use of tetracycline in poultry farming could result in horizontal transfer of resistance determinates from poultry to humans as well as to the environment. Escherichia coli, is a commensal bacteria from human and poultry digestive systems, and present one of the most important reservoirs of antibiotic resistance and has a significant role in the transfer of various resistance determinants. Some strains of Escherichia coli are highly pathogenic and can cause several diseases in poultry which require antibiotic therapy. Positive correlation between the usage of antibiotics both in human and in veterinary medicine and the corresponding antibiotic resistance were reported by many authours. Furthermore, there is also some evidence that the positive correlations were also found between the usage of antibiotics in veterinary medicine and the appereance of antibiotic resistance in bacteria isolated from humans. The prudent use of tetracycline antibiotic in poultry production is essential as well as permanet monitoring of the presence of the tetracycline resistance.

Key words: Escherichia coli, poultry, resistance, tetracycline

\footnotetext{
${ }^{1}$ Corresponding author: dragana@niv.ns.ac.rs
} 


\title{
REZISTENCIJA NA TETRACIKLIN KOD IZOLATA ESCHERICHIA COLI ŽIVINE
}

\author{
Dragana Ljubojevićc ${ }^{1}$ Maja Velhner ${ }^{1}$, Dalibor \\ Todorović ${ }^{1}$, Marko Pajić ${ }^{1}$, Dubravka Milanov ${ }^{1}$ \\ Naučni institut za veterinarstvo“Novi Sad”, Novi Sad, Serbia
}

\section{Kratki sadržaj}

Predmet ovog rada je analiza i poređenje rezultata iz raspoložive literature u pogledu prevalentnosti rezistencije na tetracikline sojeva Escherichia coli izolovanih kod živine u različitim zemljama. Tetraciklin je još uvek jedan od najčešće primenjivanih antibiotika u većini zemalja u razvoju, kako u humanoj tako i u veterinarskoj medicine. Glavni razlozi za to su njegova široka dostupnost kao i relativno niska cena. Osim toga, ova klasa antibiotika se još uvek koristi u profilaktičke i terapeutske svrhe i u razvijenim zemljama. Široka primena teteraciklina u živinarskoj industriji može da izazove horizontalni transfer determinanata rezistencije sa živine na ljude in a okolinu. Escherichia coli je komensalna bakterija prisutna u digestivnom traktu ljudi i živine pa tako i jedan od najvažnijih izvora rezistencije na antibiotike. Ovaj mikroorganizam takodje igra važnu ulogu u prenosu različitih determinanata rezistencije. Neki sojevi Escherichia coli imaju izražen patogeni potencijal i izazivaju niz oboljenja kod živine koja zahtevaju antibiotsku terapiju. Pozitivnu korelacija između primene antibiotika $\mathrm{u}$ humanoj i veterinarskoj medicine i posledičnu rezistenciju na antibiotike opisali su brojni autori. Osim toga, postoje dokazi o pozitivnoj korelaciji između primene antibiotika u veterinarskoj medicine i pojave rezistencije na antibiotike kod bakterija izolovanih kod ljudi. Pažljiva primena tetraciklina u živinarstvu je od velikog značaja kao i kontinuirani monitoring pojave rezistencije na tetracikline.

Ključne reči: Escherichia coli, živina, rezistencija, tetraciklin

\section{INTRODUCTION}

The antibiotics used in poultry farming may sometimes be the same, or belong to the same class, as those used in human medicine. The main consequences of the use of antibiotics, especially the same or from the same class, both in human and poultry can cause dissemination of antibiotic resistance as result of the continuous positive selection of resistant bacterial clones, whether 
these are pathogenic, commensal or environmental bacteria (Sengeløv et al., 2003). Antibiotic resistance occurs often in poultry farms and surrounding environment and can be spread to humans via food or water chain, and also by routes such as environmental contamination by poultry waste and direct contact with animals (Velhner et al., 2010). The resistant zoonotic bacteria are of particular public health concern. Zoonotic infection can be transmitted to humans directly from animals or through the contaminated food. During the last two decades, the use of antibiotic in poultry farming has changed, with use of antibiotics as growth promoters banned or severely restricted in some countries. This has lead to distinctive differences between countries in regard to prevalence of antibiotic resistance (Van den Bogaard et al., 2001; Adelowo et al., 2009; EFSA, 2016). Furthermore, because antibiotic use practices are very different among countries across the world we have taken the opportunity to find out more about the general effects of antibiotics, by comparing the patterns of antibiotic resistance, among poultry from different parts of the world.

This review presents the prevalence and some of the latest problems regarding tetracycline resistant Escherichia coli strains, isolated from poultry in different countries worldwide, with a focus on broiler chickens. Several reviews of antibiotic resistance in E. coli have been published recently in Serbia (Velhner et al., 2010; Todorović et al., 2015) but the problems with tetacycline resistance in $E$. coli in relation to poultry farming have not been particularly addressed.

\section{TETRACYCLINE -MODE, USE, PRICE, RESISTANCE}

The mode of action of tetracycline has been reviewed by Velhner and Milanov (2015). Briefly, it consists of reversible inhibition of bacterial protein synthesis by binding to the ribosomal complex, preventing the association of aminoacyl-tRNA with the bacterial ribosome. The consequence is weakening the ribosome-tRNA interaction and stopping the synthesis of proteins.

Tetracycline are a family of broad-spectrum antibiotics that are frequently used in poultry production. First-generation, such as tetracycline, chlortetracycline, and oxytetracycline, have been widely used as growth promoters in poultry production for decades and the second-generation, such asminocycline and doxycycline, are commonly used both in the prophylactic and therapeutic purpose in human and veterinary medicine (Eliopoulos and Roberts, 2003; Nsofor et al., 2013). Tetracyclines are used for all food production animal species, including poultry. The main reasons are their broad spectrum of activities, the relatively low price and availability. On the other hand, the 
extensive usage of tetracycline may often lead to the emergence of resistant bacteria (Chopra and Roberts, 2001). The extended use of tetracycline leads to the selection pressure and consequently the fact that tetracycline resistance is very frequent in zoonotic, pathogenic, intestinal, commensal bacteria such as E. coli.

The study conducted by Bryan et al. (2004) indicated that the environmental exposure of humans and animals to tetracycline and also the other antibiotics leads to the development and dissemination of antibiotic resistance by horizontal gene transfer. The continuous search for new antibiotics in the time of resistance is response to reduced utility of tetracycline (Chopra and Roberts, 2001). The continued transfer of antibiotic resistance determinants among various environmental and clinical bacterial populations is a permanent problem.

\section{THE USE OF TETRACYCLINE IN HUMAN CLINICAL PRACTICE}

Tetracycline as a broad-spectrum antibiotics are still used in clinical practice in human medicine although with some limitation (Chopra and Roberts, 2001). As one of the cheapest classes of antibiotics available today, they are very suitable for use in developing countries. Tetracycline's are effective for the therapy of human parasitic diseases, so they are the drug of choice in the therapy of mefloquine-resistant Plasmodium falciparum infection (Eliopoulos and Roberts, 2003). Tetracyclines are used for treatment of diseases caused by Gram-negative, gram-positive bacteria, chlamydia, mycoplasmas, rickettsia and protozoan parasites and also as growth promoters in livestock production worldwide (Velhner and Milanov, 2015).

\section{Mechanisms of resistance (Acquired tetracycline resistance genes)}

Four mechanisms such as efflux, ribosomal protection, enzymatic inactivation and target modification are recognized as mediators of tetracycline resistance in bacteria (Velhner and Milanov, 2015). The first report of transferable tetracycline resistance was in Shigella dysenteriae in 1960 (Eliopoulos and Roberts, 2003). After that 23 genes encoding efflux pump and 11 genes encoding ribosomal protection proteins in bacteria have been reported (Chopra and Roberts, 2001). The genes associated with an efflux mechanism, namely tet(A), tet(B), tet(C), tet(D), and tet(E) are important part of tetracycline resistance in E. coli (Chopra and Roberts, 2001). Bryan et al. (2004) found that the gene tet(M) is a mediator of ribosomal protection mechanism of resistance, in isolates from pig and chickens and it was the first report of tet(M) in E. coli, while 
Jones et al. (2006) first reported the identification of the tet(M) tetracycline resistant determinant in a human clinical isolate of $E$. coli.

The prevalence of tetracycline resistance in E. coli can be a useful tool to monitor resistance in poultry production and furthermore it can provide a good model for epidemiological studies of antimicrobial resistance. Tetracycline-resistant $E$. coli can be used as a useful indicator for antibiotic resistant bacteria in poultry farming due to its high occurrence. Numerous studies have demonstrated the prevalence and characterization of tetracycline resistant E. coli from broiler chickens (Sengeløv et al., 2003), laying hens (Van den Bogaard et al., 2001), humans (Miles et al., 2006), and poultry litter, facilities, manure (Adelowo et al., 2009).

\section{E. coli - commensal and pathogenic, the role in resistance}

Commensal E. coli are commmonly present in the digestive tract in humans and in animals and in feces and it is well known that E. coli could be a source of contamination of food during evisceration after slaughter, during contact with contaminated water or during food handling. Besides that, E. coli are also very important pathogen and can be involved in intestinal but also in extra-intestinal infectious diseases. Pathogenic strains of E. coli can cause respiratory disease in poultry and in such cases antibiotics are very important for the treatment of these conditions and these compounds are commonly administered as feed supplements. On the other hand, their frequent use can lead to development of multi-resistant $E$. coli. Moreover, some strains of $E$. coli are zoonotic pathogens and can be causative agents of food-borne diseases in humans. Furthermore, infections with antibiotic resistant strains of E. coli may lead to failures in clinical therapy or the use of second-line antibiotics for therapy can be required. The importance of commensal bacteria, particularly E. coli is the fact that they also can be a reservoir for resistance genes, which further may be transferred between bacterial species, including zoonotic microorganisms (Todorović et al., 2015). Apart from being one of the most important reservoirs of antibiotic resistance genes, $E$. coli could be one of the primary causes of hospital-acquired infections. It was established that the occurrence of antibiotic resistance in commensal E. coli could be used as excellent indicator of the selection pressures due to the use of antibiotics and the resistance patterns which could be expected in pathogenic bacteria. E. coli may be susceptible to many antibiotics but isolates from poultry may be frequently resistant to one or more antibiotics, and particularly to those that have been widely used in poultry farming for a long time such as tetracycline's (Zahraei Salehi and Farashi Bonab, 2006). The number of factors affects the occurrence of antibiotic resistance in commensal E. coli. For instance the 
selective pressure from the use of antibiotics in poultry, clonal spread of resistance, the dissemination of genetic determinants of resistance such as plasmids and the co-selection of multi-resistant organisms are involved in establishing the population of resistant microorganisms in animals.

\section{CORRELATION BETWEEN THE USE OF ANTIBIOTICS AND OCCURRENCE OF TETRACYCLINE RESISTANCE}

The use of antibiotics is often necessary for the therapy of bacterial infections in intensive poultry production and tetracycline is a frequently used first line antibiotic for poultry and other domestic animals. The inappropriate use of antibiotics, such as exposure of bacteria to subtherapeutic doses of antibiotic, the use of antibiotics in food producing animals, especially as growth promoters or in prophylactic purpose are the main factors which strongly contribute to the development of resistance. Also, the therapy is frequently conducted without the previously bacteriological examination and without determination of the antibiotic resistance profile of a pathogen which could lead to appearance of the antibiotic resistance (Velhner et al., 2010). Besides that, bacteria can be exposed to tetracycline in environment since tetracyclines are naturally derived compounds (Miles et al., 2006). Also there is a lacks of information regarding the amount of antibiotics administered in sub-therapeutically doses in poultry in many countries. Schroeder et al. (2004) stated that selective pressure promote the emergence of antibiotic resistance bacteria each time when antibiotics are used but it should be emphasized that sub-therapeutic use of antibiotics can be an additional factor which contribute to the emergence of antibiotic resistant bacteria.

The widespread and long use of tetracycline in the poultry industry is undoubtedly one of the reasons for the high prevalence of resistance to tetracycline's in broilers (Van den Bogaard et al., 2001) and it should be mentioned that about $50-90 \%$ of antibiotics administered to animals on farms are excreted into the environment as unmetabolized or as metabolic intermediates which are inactive but may be transformed and become active in the environment (Diarra et al., 2007). On the other hand, Álvarez-Fernández et al. (2013) found that the relatively high resistance to tetracycline in E. coli isolated from poultry from organic system of rearing is unexpected and surprising. Thibodeau et al. (2008) found resistance to tetracycline in E. coli isolated from broilers in Canada even if these flocks were not treated with antibiotics (of this class). Knežević and Petrović (2008) reported tetracycline resistance in E. coli isolates from broiler farms even if no antibiotics were used. Such finding could be explained 
by the fact that tetracycline's have been used on poultry farms for treatment of infectious diseases for a long time, so there is possibility that E. coli may evolve and become resistant to tetracycline's, which further lead to widespread distribution in animals as reservoirs regardless the type of production and the practice of using antibiotics. Moreover, Diarra et al. (2007) suggested that antibiotic resistant clones are stable and they could persist in poultry flocks during several production cycles-rotations, even in the cases when selective pressure on the farm is not present for a long period of time. So, sometimes the use of antibiotics may not be directly correlated with the antibiotic resistance rate.

The possibility of transfer of tetracycline resistant bacteria from poultry to humans is still controversial (Miles et al., 2006). Schroeder et al. (2004) stated that there is no documented case of antibiotic treatment failure of infections which is directly related to ingestion of foodborne $E$. coli and consequence of that is the fact that because of a lack of a definitive link between antibiotic resistant $E$. coli in food and failure of clinical treatment, the real degree of treat to human health due to antibiotic resistant E. coli in poultry remains putative and controversial.

\section{Cross resistance}

Velhner and Milanov (2015) highlighted the fact that tetracycline are provoking resistance to other classes of antibiotics and vice versa. Resistance to tetracycline often leads to a cross resistance to other antibiotics, such as fluoroquinolones (Todorović et al., 2015). Cross resistance of tetracyclines to fluoroquinolones and third generation of cephalosporins in E. coli from broiler chickens and fattening turkeys in 2013 and 2014 was observed in Austria, Germany, Hungary, Italy, Poland, Portugal, Spain (EFSA, 2015; 2016). Velhner and Milanov (2015) suggested that this is probably the consequence of the fact that the resistance determinants are often found on mobile genetic elements. The main consequence is threatened to humans and animals health especially in the cases when the antibiotics are necessary for the therapy of certain diseases.

\section{THE OCCURENCE OF TETRACYCLINE RESISTANCE IN POULTRY IN EUROPE}

The European Commission banned the use of antibiotics as growth promoters in animal nutrition by 1 January 2006 due to the emergence of bacteria resistant to antibiotics, which are used for the therapy of human and animal infections. Sweden banned use of antibiotics as growth promoters in all food producing animals in 1986 and after that the European Union banned use of 
avoparcin in 1997 and use of bacitracin, spiramycin, tylosin and virginiamycin in 1999 as growth promoters. Also, consumer pressure is pushing the poultry industry to produce chickens without antibiotics as growth promoters, but removal of antibiotics as growth promoters has led to reduced growth performance and feed efficiency as well as increased incidence of diseases such as clostridial necrotic enteritis in broilers (Casewell et al., 2003). Moreover, Casewell et al. (2003) noted the increase in the sales of tetracycline (by 36 tonnes) for therapeutic purposes form 1999 to 2000 after the EU ban of the above mentioned antibiotics as growth promoters.

Van den Bogaard et al. (2001) examined the percentage of faecal samples containing resistant strains of $E$. coli in three poultry population; broilers and turkeys commonly given antibiotics and laying hens treated with antibiotics relatively rarely in the Netherlands. They reported that the prevalence of resistant faecal E. coli from poultry, poultry farmers and poultry slaughters to oxytetracycline in turkeys was $87 \%$, in broilers $78 \%$ in laying hens $76 \%$, in turkey farmers $79 \%$ in broiler farmers $61 \%$ and in laying hens farmers $36 \%$ in turkey slaughters $55 \%$ and in broiler slaughters $43 \%$. They noted that for oxytetracycline the percentage of samples with a high degree of resistance in chickens and turkeys was significantly higher compared to laying hens. And the same tendency was observed in human population and also the resistance to oxytetracycline was significantly higher in slaughters than in laying-hen farmers.

Sengeløv et al. (2003) examined E. coli isolates from diseased and healthy broilers in Denmark for the presence of tetracycline resistance genes tet(A), (B), (C), (D) or (E) and found that the tet(A) and tet(B) were the most prevalent. These results is probably consequence of the fact that the tet(A) and the tet $(B)$ genes are the predominant in the intestinal environment of food producing animals and/or the presence of specific conjugative plasmids. They noted that pathogenic E. coli isolates from diseased broilers were of serogroup $\mathrm{O} 2$ or $\mathrm{O} 78$. They examined 18 tetracycline resistant pathogenic isolates of $E$. coli and 17 tetracycline isolates from healthy broilers and found that one isolate contained the tet(D) gene, while they did not detected tet(C) and tet(E) genes in any of the isolates. The authors did not observed significant difference between the prevalence of tet(A) and tet(B) genes among $E$. coli isolates originated from healthy and diseased broilers. In isolates form healthy broilers tet(A) was present in $41.2 \%$ and tet(B) in $52.9 \%$ and tet(D) in $5.9 \%$ and in isolates originated from diseased broilers tet(A) was present in $72.2 \%$ and tet(B) in $27.8 \%$ samples.

Lanz et al. (2003) examined occurrence of antibiotic resistance on clinical E. coli isolates from laying hens with septicemia collected in Switzerland between 1999 and 2001 and reported that resistance to tetracycline in laying hens 
was $26 \%$. They found that the frequency of resistance determinants among tetracycline -resistant and tetracycline intermediate isolates in laying hens was $64 \%$ for tet(A), $30 \%$ for tet(B), $0 \%$ for tet(C) and in $6 \%$ of isolates they did not find any of the resistance determinants, while tet(D) and tet(E) genes were not detected in any of the $E$. coli isolates.

Marchant et al. (2013) examined isolates of the E. coli from healthy chickens belonging to the oldest (1998/99) and the latest (2006) surveillance programs in Spain. They noted correlation between the presence of integrons and resistance to tetracycline in chicken E. coli isolates from the Veterinary Antimicrobial Resistance Surveillance (VAV) Network and according to their data integrons were detected in $49 \%$ of the isolates from 1999 while resistance to tetracycline was determined in $94 \%$ of isolates. Integrons were present in $49 \%$ of isolates from 2006 while resistance to tetracycline was determined in $80 \%$ of E. coli isolates.

Resistance to tetracycline in broilers was very high or extremely high in most countries of the EU in 2014, with the exception of the Nordic countries (Finland, Denmark, Norway and Sweden) which reported low to moderate resistance to tetracycline, and the overall tetracycline resistance in EU was $50.1 \%$ (EFSA, 2016). The highest levels of resistance from fattening turkeys was reported for tetracycline and it was 70.9\% in E. coli isolates in 2014 (EFSA, 2016). The occurrence of tetracycline resistance in $E$. coli isolates also varied significantly between European countries in 2013 and the resistance level to tetracycline in EU in broilers to tetracycline was $45.6 \%$ (EFSA, 2015).

The occurrence of resistance to tetracycline in indicator E. coli from Gallus gallus in countries reporting MIC data in 2013, using harmonized ECOFFs was as follows: $22.6 \%$ in Austria, $60.3 \%$ in Belgium, $56.0 \%$ in Croatia, 15.2\% in Denmark, 65.8\% in France, 35.2\% in Germany, 37.5\% in Hungary, 35.8\% in Netherlands, $46.1 \%$ in Poland, $64.1 \%$ in Spain, $7 \%$ in Norway and $23.8 \%$ in Switzerland (EFSA, 2015).

Furthermore, the occurrence of resistance to tetracycline in indicator $E$. coli from Gallus gallus in countries reporting MIC data in 2014 was as follows: 29\% in Austria, 45.6\% in Belgium, 43.5\% in Croatia, 5.8\% in Denmark, 63.3\% in France, 33.9\% in Germany, 39.4\% in Hungary, $42.4 \%$ in Netherlands, $62 \%$ in Poland, $60.6 \%$ in Spain, $1.5 \%$ in Norway, $96.5 \%$ in Bulgaria, $78.2 \%$ in Cyprus, 24\% in Czech Republic, 18.3\% in Estonia, 10.9\% in Finland, 68\% in Greece, $52.7 \%$ in Ireland, $73.5 \%$ in Italy, $53.1 \%$ in Latvia, $56.1 \%$ in Lithuania, 45\% in Malta, 62.6\% in Portugal, $73.8 \%$ in Romania, 43.5\% in Slovakia, 31.8\% in Slovenia, 9.6\% in Sweden and 60.4\% in United Kingdom (EFSA, 2016). Regarding the trends in resistance among commensal E. coli isolates from broil- 
ers over the seven year period from 2008 to 2014, the Netherlands registered significant declines in tetracycline resistance over the last 5 years and statistically significant decreasing trends over years was observed for tetracycline in France (EFSA, 2016).

Resistance to tetracycline in E. coli from fattening turkeys was generally very high or extremely high and amounted from $23.7 \%$ to $87.6 \%$ in EU countries in 2014 (EFSA, 2016). Extremely high levels $(>70 \%)$ were reported in France (75.2\%), Italy (77.6\%), Poland (73.5\%), Portugal (85.9\%), Romania (84.2\%), Spain (87.6\%), UK (79.2\%). Very high (50-70\%) resistance levels to tetracycline were observed in Germany (56.5\%), Hungary (64.1\%); while high (20-50\%) resistance levels were reported in Austria (40.8\%) and in Sweden (23.7\%) (EFSA, 2016).

\section{THE OCCURENCE OF TETRACYCLINE RESISTANCE IN POULTRY IN AFRICA}

Generally, in Africa the use of antibiotic in food producing animals, including poultry is unrestricted and the policies regarding antibiotics are not often enforced, so antibiotics, especially tetracycline are widely used in poultry production (Nsofor et al., 2013; Olonitola et al., 2015). According to study conducted by Nsofor et al. (2013) more than $83 \%$ of poultry farmers use tetracycline, and they are the most widely used in poultry feeds in Africa and as a consequence $100 \%$ of the bacterial isolates from tested feeds were resistant to tetracycline. Furthermore, in the majority of countries a prescription for antibiotics is not need even for human use (Olonitola et al., 2015) and the antibiotics that are used both human and in veterinary medicine is important, especially having in mind that even the use of distinct antibiotics can be a risk for developing of resistance. Olonitola et al. (2015) mentioned the fact that there is a great shortage in data related to the emergence of antibiotic resistant pathogens in Africa, but undoubtedly African communities suffer from infections with antibiotic resistant bacteria.

Adelowo et al. (2009) examined the prevalence of multi-resistant bacteria in the waste dumpsite on ten poultry farms in Nigeria. The resistance to tetracycline was $100 \%$ among the isolated $E$. coli strains. They noted that the antibiotics which are used frequently in the farms have caused the higher rate of resistance in bacteria. Such was the case with the tetracycline, oxytetracycline and chlortetracycline which were used regularly on ten farms, which they have studied.

Olonitola et al (2015) also stated that tetracycline's are one of the most 
often used antibiotics in Nigeria not only in veterinary medicine, but also in human clinical practice. The main reason is the fact that tetracycline is highly available and its price is relatively low. The use of tetracycline in poultry production could lead to horizontal gene transfer via bacteria which colonized intestinal tract, such as E. coli.

The authors from Nigeria showed that tetracycline resistance is present in the examined poultry and poultry farms as well as in the facillities surrounding the farms and they all highlighted the need for strict regulation and control of tetracycline use in poultry farming in Nigeria as well as in other African countries. They further stated that the use of antibiotics, including tetracycline which is without control in poultry industry, present a serious problem from the public health point of view, having in mind the possibility of dissemination of resistant strains from poultry to environment, and spread of resistance determinants to pathogenic strains of bacteria in Nigeria.

\section{THE OCCURENCE OF TETRACYCLINE RESISTANCE IN POULTRY IN NORTH, CENTRAL AND SOUTH AMERICA}

In the United States some antibiotics are used for prophylactic purposes in livestock or as growth promoters. Tetracycline have been used as a useful growth promoters in farm animals in North America since the 1950s (Eliopoulos and Roberts, 2003). For the first time in experimental purposes, in the USA Levy et al. (1976) fed chickens with tetracycline supplemented feed and as they expected the intestinal microbiota of the chickens contained almost entirely tetracycline resistant bacteria. Furthermore, they also showed that feeding chickens with tetracycline-supplemented feed lead to the emergence of tetracycline-resistant $E$. coli in people from that farm, but not their neighbors.

Diarra et al. (2007) examined the effect of addition of approved antibiotics such as bambermycin, penicillin, salinomycin, and bacitracin or a combination of salinomycin plus bacitracin in British Columbia (Canada) on the prevalence and distribution of antibiotic resistance in 197 commensal E. coli isolates from broiler chickens over 35 days and reported that all isolates showed some degree of multiple antibiotic resistance. They observed that the resistance to tetracycline was most prevalent and amounted 68.5\%. Furthermore, they noted that the overall resistance levels decreased from day 7 to day 35 . They further characterized 104 tetracycline resistant E. coli isolates from 7 to 28 days old chickens fed different growth promoters and detected a decrease in the incidence of isolates carrying tet(B) gene from days 7 to 35 , so their results demonstrated that multi-resistant strains of $E$. coli may be isolated from broil- 
ers regardless of the antibiotics used as growth promoters. On the other side, the phenotype and the distribution of resistance determinants in E. coli can be changed by feed with the addition of some of the antibiotics used in broilers farming.

Miles et al. (2006) investigated the prevalence of tetracycline resistance in fecal $E$. coli isolates from healthy broiler chickens and compared obtained results with isolates obtained from hospitalized patients in Jamaica. They examined eighty-two E. coli strains isolated from faecal samples of broiler chickens and urine and wound specimens of hospitalized patients. According to their results tetracycline resistance occurred at a frequency of $82.4 \%$ in isolates from broilers compared to $43.8 \%$ in human isolates. Moreover, they detected multi-resistant strains in isolates from both chickens and humans and noted that it was usually associated with tetracycline resistance. Isolates resistant to tetracycline from both sources contained one or several plasmids which were transmissible by transformation of chemically-competent $E$. coli. They also observed that tetracycline resistance was mediated by efflux genes tet(B) and/or tet(D). The results obtained by Miles et al (2006) highlighted the prevalence of multi-resistant strains of $E$. coli among healthy broilers in Jamaica and possibility that it is associated with expression of tetracycline resistance. They noted that the genes which encode resistance were similar in the strains from chickens and human origin and suggested that genes are disseminated in the environment but they did not find any tetracycline resistant E. coli isolates from feed and water samples from any of the five tested poultry farms so the further investigations are required to examine the possibility of chicken sources as potential reservoirs for tetracycline resistance in humans. Further, they noted that most multi-resistant strains isolated from chickens were resistant to kanamycin, tetracycline and nalidixic acid and the most isolates from humans were resistant to kanamycin and tetracycline or kanamycin and gentamicin and that fact suggested that isolates from chickens that were resistant to tetracycline are more likely to become resistant to other antibiotics. On the other hand, they found that strains which were resistant to tetracycline isolated from chickens were susceptible to ampicillin, amoxicillin/clavulanate, chloramphenicol, ciprofloxacin and gentamicin and these findings indicated limited cross-resistance which enables the existence of therapeutic options for poultry colonized by tetracycline resistant $E$. coli. They also provided the evidence of existing significant tetracycline resistance in E. coli isolates from chickens originated from farms without recorded use of antibiotics and hospitalized patients in Jamaica. Further, they reported that tetracycline resistance was associated with plasmids and they discovered that $69 \%$ of the tetracycline resistant isolates had 
resistance plasmids. Based on their results Miles et al. (2016) further suggested that many human and poultry commensal bacteria carry the same tet genes, plasmids, transposons and integrons as pathogenic bacteria and that all these resistance determinates could be transferred to pathogenic bacteria which can cause disease.

Ferreira et al. (2016) examined cloacal swabs which were harvested from 2011 to 2012 from 40-day old commercial broilers in two poultry farms from São Paulo State, Brazil for the presence of Extended-spectrum $\beta$-lactamase (ESBL) producing Enterobacteriaceae. They detected 13 ESBL-producing E. coli and observed that among the isolates, $92.3 \%$ were also resistant to tetracycline's.

\section{THE OCCURENCE OF TETRACYCLINE RESISTANCE IN POULTRY IN ASIA AND MIDDLE EAST}

The majority of antibiotics is used for prophylactic purposes in livestock or as growth promoters in China and the same situation is also recorded in many developing countries in Asia and Middle East. The results of research from various authors (Dai et al., 2008; Lei et al., 2010) showed that expansion of poultry production in China and the accompanying widespread use of antibiotics have resulted in widespread resistance to antibiotics, especially to tetracycline.

Dai et al (2008) investigated antibiotic resistance of E. coli isolated from chickens from 49 farms located in southern, central and northern China between 2001 and 2006 and found that the most common pattern of resistance was ampicillin-enrofloxacin-doxycycline resistance, which was observed in $125(23.3 \%)$ of the E. coli isolates. The resistance to doxycycline was observed in $75.0 \%$ of isolates and it was consistently high (over 70\%) from 2001 to 2006. According to their results resistance to doxycycline was found in $70.9 \%$ in $2001,74.4 \%$ in $2002,72.2 \%$ in $2003,72.4 \%$ in $2004,77.8 \%$ in 2005 and $82.4 \%$ in 2006, so in total during six years number of investigated isolates was 536 and resistance to doxycicline was $75 \%$ (402 isolates).

Lei et al. (2010) provided evidence of the relationship of the use of antibiotics in poultry farming and its selection of antibiotic resistance in E. coli isolates from broilers and their results showed very high resistance to tetracycline in China. They examined $187 \mathrm{E}$. coli isolates from chicken and found that the level of resistance to tetracycline was $95.2 \%$. Based on the obtained data, they noted that China faced with serious problem, and that the practice of abundant use of antibiotics, including tetracycline in poultry, especially in poultry feed as additives, consequently lead to high resistance in $E$. coli isolates. 
Salehi and Bonab (2006) investigated 50 avian pathogenic E. coli (APEC) strains isolated from broilers with colisepticemia and found that the rate of resistance to oxytetracycline was $95 \%$, to chlortetracycline was $95 \%$, to tetracycline was $94 \%$ and to doxycycline was $88 \%$. Their results showed a very high incidence of resistance to tetracycline in E. coli strains from poultry in Iran and the obtained results is probably due to the increased use of antibiotics as feed additives for growth promotion and prevention of diseases, as well as the use of inappropriate antibiotics for treatment of the disease. They also reported that antibiotics are used intensively in order to decreasing the huge losses caused by colibacillosis caused by E. coli in poultry farming in Iran. The resistance transfers among different bacteria and possible cross resistance between antibiotics used in poultry farming are also significant factors that contribute to high level of tetracycline resistance in E. coli isolates from poultry in Iran.

Van et al. (2008) examined a current resistance profile of $E$. coli from poultry in Vietnam. They isolated E. coli from 43 samples of broilers feces and noted that the rates of multiresistance were up to 95 in chicken feces isolates and resistance was most frequently observed to tetracycline (95\%). They collected faeces from two poultry farms where chickens were less than 1 month old. They further reported that the tet(A) gene was the most prevalent of the tetracycline resistance genes detected (71.1\% of the isolates), followed by tet(B) (18.4\%) in Vietnam.

Ozaki et al. (2011) investigated the effects of rearing practices of commercial broilers on the incidence of antibiotic resistance in commensal E. coli isolates in Japan so they collected fecal E. coli isolates from 4 farms wherein in 2 out of 4 farms no antibiotics were used during the rearing period and antibiotics had not been used in farming practice for more than 1 year, whereas on the other two farms, following collection of the fecal samples at 14 and 15 days of age, oxytetracycline, sulfadimethoxine, and tylosin were given to chickens on one farm and sulfadimethoxine was given to chickens on the other farm. They reported resistance to oxytetracycline in 46 to $62 \%$ of isolates obtained from farms 1, 2 and 4 while $100 \%$ of the isolates from farm 3 were resistant to oxytetracycline. They found that the level of resistance to oxytetracycline on farm 1 at 2, 17 and 50 days of age was $38 \%, 57 \%$ and $45 \%$, respectively; on farm 2 at 2,17 and 48 days of age resistance to oxytetracycline was 53\%, 29\% and 78\%, respectively; on farm 3 at age 2, 14 and 47 days the resistance rate amounted $100 \%$; on farm 4 at age 2, 15 and 48 days the resistance rate amounted $67 \%$, $49 \%$ and $70 \%$, respectively. They suggested that isolates resistant to oxytetracycline from the farm where antibiotic were not used were shed from the intestinal tract and remained in the environment. It has been well documented in the 
study conducted by Diarra et al. (2007) that some resistant strains can persist in the farm environment and colonize new flocks. The authors also stated that it was not known whether antibiotics had been used in broiler parent flocks. It is well known that such practices can affect prevalence of resistant strains in commercial broiler farms without using antibiotics in feed. The author also strongly suggested that the acquired resistance to antibiotics including tetracycline occurred due to horizontal transmission of resistant plasmids regardless of the use of antibiotics during the rearing period.

\section{THE OCCURENCE OF TETRACYCLINE RESISTANCE IN POULTRY IN SERBIA}

The few studies have investigated antibiotic resistance, including tetracycline resistance, in E. coli from the poultry farms in Republic of Serbia (Krnjajić et al., 2005; Knežević and Petrović, 2008). Krnjajić et al. (2005) took samples from 42 cattle, pig and poultry farms. The samples were feces of young healthy, young unhealthy and adult animals or internal organs, cloacal swabs and eggs in case of dead animals. Prevalence of resistance to tetracycline of the isolated E. coli strains isolated from healthy chicken was a $100 \%$, in case of dead chicken, the isolated E. coli strains showed a $85 \%$ resistance to tetracycline, while the prevalence of tetracycline resistance of the $E$. coli strains from hens was $75 \%$. Knežević and Petrović (2008) examined the resistance in commensal non-pathogenic E. coli from three farms from Vojvodina. They chose commensal strains because they represent a good indicator of commensal resistance and as opportunistic pathogens may spread resistance genes by horizontal gene transfer to other bacteria, including pathogens. They sampled sixty rectal or cloacal swabs from randomly selected animals settled in different objects without direct contact including 20 broilers which were 6 week old from three different farms. They reported that the broilers were not treated with antibiotics. They grouped intermediate strains with the sensitive isolates. Among E. coli isolates from broilers the $94.7 \%$ isolates were resistant to tetracycline. The authors claimed that the high resistance rate to tetracycline of broiler isolates is not associated with its usage. Gavrović et al. (2011) examined samples of internal organs, feces and swabs from ill animals, including poultry and they found that the incidence of resistance to tetracycline in E. coli isolated from poultry was $56 \%$. 


\section{THE OCCURENCE OF TETRACYCLINE RESISTANCE IN POULTRY IN AUSTRALIA}

The use of antibiotics in Australia in animal production is regulated and enforced. Obeng et al. (2012) examined 251 E. coli isolates from intensive meat and free range egg layer chickens collected between December 2008 and June 2009 in South Australia. For that purpose they collected a total of 311 faecal samples including 155 from free range meat chickens, 69 from free range egg layer chickens and 87 from indoor commercial chickens and found that phenotypic resistance to tetracycline varied between different classes of poultry. Tetracycline resistance was identified in 53 (39.5\%) of free range meat chicken isolates, 39 (67.2\%) of indoor commercial meat chickens and in 10 (16.9\%) of the free range layers. In total of $251 \mathrm{E}$. coli isolates the abundant resistance was detected to tetracycline (40.6\%). Furthermore, they found multiple resistances to three or more antibiotics in $26(10.6 \%)$ of the 251 isolates and co-resistance involving tetracycline was the most prevalent detected. They found the tet(A) gene in 48 isolates, the tet(B) in 7 isolates, the both tet(A) and tet(B) genes in one isolate, tet $(\mathrm{A})$ and tet $(\mathrm{C})$ genes in 11 isolates and the combination of tet(B) and tet $(\mathrm{C})$ genes in 3 isolates.

The prevalence of tetracycline resistance and the occurrence of resistance genes detected in the $E$. coli isolates in relation to distribution in the various groups of chickens were as follows: in free range meat chickens tet(A) was found in 20 , tet(B) in 1 ; tet $(A)$ and tet(C) in 4 ; tet(B) and tet(C) in 2 and Integron 1 in 20 and Integron 2 in 6 isolates; in free range egg layers tet(A) was detected in 3 , tet(B) in 3 isolates, while no integrons were found; in indoor commercial meat chickens tet(A) was found in 25 , tet(B) in 3 , tet(A) and tet(B) in $1, \operatorname{tet}(\mathrm{A})$ and tet $(\mathrm{C})$ in $7, \operatorname{tet}(\mathrm{B})$ and tet(C) in 1 , Integron 1 in 13 and Integron 2 in 1 isolate. They found association between tetracycline resistance and integrons, and in total of 251 isolates, tetracycline resistance was detected in 102 isolates $(40.6 \%)$ and Integron 1 was found in $33(13.1 \%)$ of the isolates while Integron 2 was found in $7(2.8 \%)$ of the isolates. The authors highlighted the fact that their results showed a considerable reduction in resistance to tetracycline in comparison with previous study of intensively reared chicken conducted in their laboratory which has shown resistance to tetracycline in $85 \%$ of isolates and they concluded that tetracycline resistance are determined by the antibiotic used. In Australia only chlortetracycline is registered for therapy of egg-producing birds, which explains in part the low level of tetracycline resistance in free range birds. A wider range antibiotic such as oxitetracycline is registered for use in meat producing birds. Furthermore, authors included 
the possibility of residual resistance to tetracycline due to co-selection. The authors highlighted the fact that there were no significant differences between intensive and free-range chickens in occurrence of resistance but they explained that by the fact that they supplied the free-range chickens from the same hatcheries as intensive producer chicken so there is a possibility that resistance genes are passed vertically from breeder flock and that antibiotics are probably used in breeder flock rather than in the meat type chickens.

\section{Management practices and preventive measures on poultry farms}

The microbiota of poultry intestines is influenced by management practices including feeding and antibiotic use on the poultry farms. The monitoring of antibiotic resistance in commensal $E$. coli isolated from randomly selected healthy poultry, provides valuable information on the levels of the resistance in that population. In addition, determining the occurrence of resistance to antibiotics in commensal $E$. coli provides information useful for the examination of the relationship of the selective pressure exerted by the use of antibiotics on the intestinal microbiota in poultry.

It should be mentioned that epidemiological data implicate that urinary tract infections in humans may be associated with poultry consumption (Manges et al., 2007). Such data endorses the need for more rigorous surveillance and improved practises in poultry production in order to reduce the carriage of genes of antibiotic resistance and thereby minimize the likelihood of horizontal gene transfers of these resistance determinats via the food chain.

Presented data emphasize the need for further improvements of poultry farming practice, mainly the strict regulation of antibiotic usage. The proper measures can reduce the likelihood of horizontal gene transfer of mobile antibiotic resistance genes to other bacteria via the food chain. The presented data also suggested that $E$. coli strains resistant to tetracyclines are stable and able to transmit and persist in poultry even when there are no selective pressures of antibiotics or long time after the withdrawal of antibiotics.

\section{CONCLUSIONS}

The relationship between the use of tetracycline as growth promoter in poultry industry and development of resistance has been established by many authors during the past decades. Such long-term subtherapeutic use of tetracycline antibiotics in feed is of great concern because it leads to selective pressure on the E. coli carried by the poultry and also in the farms environment, so the beneficial effects of tetracycline will become limited as bacterial 
resistance increases. The necessity to reduce nontherapeutic use of tetracycline in poultry industry is obvious. Moreover, the education of the farmers, veterinarians, public and health is very important in order to ensure the proper use of tetracycline and to ensure that they will not be used without need, such as treatment of infections caused by viruses, prophylactic use and the use as growth promoter.

All in all, resistance to tetracycline in E. coli from poultry has been reported worldwide. Generally, it is often associated with the use of antibiotics, but the tetracycline resistance was noted also in several cases when antibiotics are not being used.

Monitoring of tetracycline resistance among commensal bacteria such as E. coli is of great importance not only in humans but also in poultry in order to detect the possible route of transfer of resistant bacteria or resistant determinants from poultry to humans.

\section{ACKNOWLEDGMENT}

This work has been funded by the Ministry of Education, Science and Technological Development of the Republic of Serbia, Project number TR 31084.

\section{NOTE}

The paper was presented in form of abstract at Second International Symposium of Veterinary Medicine”, (ISVM2016) Belgrade, 2016.

\section{REFERENCES}

1. Adelowo O.O., Ojo F.A., Fagade O.E.: Prevalence of multiple antibiotic resistance among bacterial isolates from selected poultry waste dumps in Southwestern Nigeria. World Journal of Microbiology and Biotechnology, 25, 713-719, 2009

2. Álvarez-Fernández E., Cancelo A., Díaz-Vega C., Capita R., Alonso-Calleja, C.: Antimicrobial resistance in E. coli isolates from conventionally and organically reared poultry: A comparison of agar disc diffusion and Sensi Test Gram-negative methods. Food Control, 30, 227-234, 2013

3. Bryan A., Shapir N., Sadowsky M.J.: Frequency and distribution of tetracycline resistance genes in genetically diverse, nonselected, and nonclinical Escherichia coli strains isolated from diverse human and animal sources. Applied and Environmental Microbiology, 70, 2503-2507, 2004 
4. Casewell M., Friis C., Marco E., McMullin P., Phillips I.: The European ban on growth-promoting antibiotics and emerging consequences for human and animal health. Journal of antimicrobial chemotherapy, 52, 159-161, 2003

5. Chopra I., Roberts M.: Tetracycline antibiotics: Mode of action, applications, molecular biology, and epidemiology of bacterial resistance. Microbiology and Molecular Biology Reviews, 65, 232-260, 2001

6. Dai L., Lu L.M., Wu C.M., Li B.B., Huang S.Y., Wang S.C., Qi Y.H., Shen, J.Z.: Characterization of antimicrobial resistance among Escherichia coli isolates from chickens in China between 2001 and 2006. FEMS microbiology letters, 286, 178-183, 2008

7. Diarra M.S., Silversides F.G., Diarrassouba F., Pritchard J., Masson L., Brousseau R., Bonnet C., Delaquis P., Bach S., Skura B.J., Topp, E.: Impact of feed supplementation with antimicrobial agents on growth performance of broiler chickens, Clostridium perfringens and Enterococcus counts, and antibiotic resistance phenotypes and distribution of antimicrobial resistance determinants in Escherichia coli isolates. Applied and Environmental Microbiology, 73, 6566-6576, 2007

8. European Food Safety Authority (EFSA): EU Summary Report on antimicrobial resistance and indicator bacteria from humans, animalis and food in 2013, EFSA Journal, 13, 2, 4036, 2015

9. European Food Safety Authority (EFSA): The European Union summary report on antimicrobial resistance in zoonotic and indicator bacteria from humans, animals and food in 2014. EFSA Journal, 14, 2, 4380, 2016

10. Eliopoulos G.M., Roberts, M.C.: Tetracycline therapy: update. Clinical infectious diseases, 36, 462-467, 2003

11. Ferreira J.C., Penha Filho R.A.C., Andrade L.N., Junior A.B., Darini, A.L.C.: Evaluation and characterization of plasmids carrying CTX-M genes in a non-clonal population of multidrug-resistant Enterobacteriaceae isolated from poultry in Brazil. Diagnostic Microbiology and Infectious Disease, http://dx.doi.org/10.1016/j.diagmicrobio.2016.05.011, 2016

12. Gavrović M., Ašanin R., Mišić D., Jezdimirović M., Žutić, M.: Investigation of the sensitivity of $E$. coli strains isolated from domestic animals to antibiotics and hemiotherapeutics in vitro. Acta Veterinaria, 61, 21-31, 2011

13. Jones C.H., Tuckman M., Murphy E., Bradford, P.A.: Identification and sequence of a tet $(\mathrm{M})$ tetracycline resistance determinant homologue in clinical isolates of Escherichia coli. Journal of bacteriology, 188, 7151-7164, 2006

14. Knežević P., Petrović, O.: Antibiotic resistance of commensal Escherichia coli of food producing animals from three Vojvodinian farms, Serbia. International Journal of Antimicrobial Agents, 31, 360-363, 2008 
15. Krnjaić D., Mišić D., Ašanin, R.: Investigation of sensitivity and resistance to antibiotics and chemotherapeutics in E. coli strains isolated from animals bred in intensive farming conditions. Acta Veterinaria, 55, 501-509, 2005

16. Lanz R., Kuhnert P., Boerlin, P.: Antimicrobial resistance and resistance gene determinants in clinical Escherichia coli from different animal species in Switzerland. Veterinary microbiology, 91, 73-84, 2003

17. Lei T., Tian W., He L., Huang X.H., Sun Y.X., Deng Y.T., Sun Y., Lv D.H., Wu C.M., Huang L.Z., Shen, J.Z.: Antimicrobial resistance in Escherichia coli isolates from food animals, animal food products and companion animals in China. Veterinary microbiology, 146, 85-89, 2010

18. Levy S.B., FitzGerald G.B., Macone A.B.: Changes in intestinal flora of farm personnel after introduction of a tetracycline-supplemented feed on a farm. New England Journal of Medicine, 295, 583-588, 1976

19. Manges A.R., Smith S.P., Lau B.J., Nuval C.J., Eisenberg J.N., Dietrich P.S., Riley L.W.: Retail meat consumption and the acquisition of antimicrobial resistant Escherichia coli causing urinary tract infections: a case-control study. Foodborne pathogens and disease, 4, 419-431, 2007

20. Marchant M., Vinué L., Torres C., Moreno M.A.: Change of integrons over time in Escherichia coli isolates recovered from healthy pigs and chickens. Veterinary microbiology, 163, 124-132, 2013

21. Miles T.D., McLaughlin W., Brown P.D.: Antimicrobial resistance of Escherichia coli isolates from broiler chickens and humans. BMC Veterinary Research, 2:7, 2006

22. Nsofor C.A., Olatoye I.O., Amosun E.A., Iroegbu C.U., Davis M.A., Orfe L.H., Call D.R.: Escherichia coli from Nigeria exhibit a high prevalence of antibiotic resistance where reliance on antibiotics in poultry production is a potential contributing factor. African Journal of Microbiology Research, 7, 4646-4654, 2013

23. Obeng A.S., Rickard H., Ndi O., Sexton M., Barton, M.: Antibiotic resistance, phylogenetic grouping and virulence potential of Escherichia coli isolated from the faeces of intensively farmed and free range poultry. Veterinary microbiology, 154, 305-315, 2012

24. Olonitola O.S., Fahrenfeld N., Pruden A.: Antibiotic resistance profiles among mesophilic aerobic bacteria in Nigerian chicken litter and associated antibiotic resistance genes. Poultry science, 94, 867-874, 2015

25. Ozaki H., Esaki H., Takemoto K., Ikeda A., Nakatani Y., Someya A., Hirayama N., Murase, T.: Antimicrobial resistance in fecal Escherichia coli isolated from growing chickens on commercial broiler farms. Veterinary microbiology, 150, 132-139, 2011 
26. Schroeder C.M., White D.G., Meng, J.: Retail meat and poultry as a reservoir of antimicrobial-resistant Escherichia coli. Food Microbiology, 21, 249-255, 2004

27. Sengeløv G., Halling-Sørensen B., Aarestrup, F.M.: Susceptibility of Escherichia coli and Enterococcus faecium isolated from pigs and broiler chickens to tetracycline degradation products and distribution of tetracycline resistance determinants in E. coli from food animals. Veterinary microbiology, 95, 91-101, 2003

28. Thibodeau A., Quessy S., Guévremont E., Houde A., Topp E., Diarra M.S., Letellier A.: Antibiotic resistance in Escherichia coli and Enterococcus spp. isolates from commercial broiler chickens receiving growth-promoting doses of Bacitracin or Virginiamycin. Canadian Journal of Veterinary Research, 72, 129-136, 2008

29. Todorović D., Velhner M., Ljubojević D., Pajić M., Milanov D.: Resistance to fluoroquinolones in Escherichia coli from pigs. Archives of Veterinary Medicine, 8, 2, 103 - 112, 2015

30. Van den Bogaard A.E., London N., Driessen C., Stobberingh, E.E.: Antibiotic resistance of faecal Escherichia coli in poultry, poultry farmers and poultry slaughterers. Journal of Antimicrobial Chemotherapy, 47, 763-771, 2001

31. Van T.T.H., Chin J., Chapman T., Tran L.T., Coloe, P.J.: Safety of raw meat and shellfish in Vietnam: an analysis of Escherichia coli isolations for antibiotic resistance and virulence genes. International journal of food microbiology, 124, 217-223, 2008

32. Velhner M., Milanov D.: Resistance to tetracycline in Escherichia coli and Staphylococcus aureus: brief overview on mechanisms of resistance and epidemiology. Archives of Veterinary Medicine, 8, 1, 27-36, 2015

33. Velhner M., Petrović J., Stojanov I., Ratajac R., Stojanović D.: Mehanizmi prenošenja rezistencije kod bakterija, Archives of Veterinary Medicine, 3, 1, 85-92, 2010

34. Zahraei Salehi T, Farashi Bonab S., Antibiotics susceptibility pattern of Escherichia coli strains isolated from chickens with colisepticemia in Tabriz province, Iran. International Journal of Poultry Science, 5, 677-684, 2006

Primljeno: 19.09.2016.

Odobreno: 15.09.2016. 